\title{
Envelhecimento com dependência: o que mostra o cinema
}

\author{
Dependent aging: what does cinema show?
}

Stela Nazareth Meneghel (https://orcid.org/0000-0002-7219-7178_ 1

Maria Cecília de Souza Minayo (https://orcid.org/0000-0001-6187-9301) ${ }^{2}$

${ }^{1}$ Escola de Enfermagem, Universidade Federal do Rio Grande do Sul. R. São Manoel 963, Rio Branco. 90620-110 Porto Alegre RS Brasil.

stelameneghel@gmail.com

${ }^{2}$ Departamento de Estudos sobre Violência e Saúde Jorge Careli, Escola Nacional de Saúde Pública Sergio Arouca, Fiocruz. Rio de Janeiro RJ Brasil.

\begin{abstract}
This paper is an essay that understands art, particularly cinema, as a complementary resource for discussing health issues, and it is part of a reflection on multicentric research on dependent older adults conducted in eight Brazilian cities. The paper analyzes two movies that address the contingencies of dependent old age and the relationship between caregivers and people cared for. "Poetry" shows the impasses of an elderly woman who is economically and emotionally overburdened, with early symptoms of Alzheimer's disease. The second movie, "What ever happened to Baby Jane?" exposes the delicate and complex relationship between the caregiver and cared person dyad. The paper aims to broaden the understanding of social processes such as aging, through cinema, encouraging the use of movies in continuing education settings involving researchers, students, and health workers.
\end{abstract}

Key words Aging, Cinema, Dependency, Qualitative research
Resumo Este artigo é um ensaio que pensa a arte, particularmente o cinema, como recurso complementar para a discussão de temas de saúde. $O$ texto faz parte da reflexão produzida no âmbito de uma pesquisa multicêntrica sobre idosos com dependência realizada em oito cidades brasileiras. Analisam-se dois filmes que abordam as contingências de uma velhice com dependência e a relação entre pessoas que cuidam e que são cuidadas. "Poesia" mostra os impasses de uma idosa sobrecarregada economica e emocionalmente que começa a apresentar sintomas da doença de Alzheimer. O segundo filme "O que terá acontecido com Baby Jane?" expõe a delicada e complexa relação entre a díade cuidador e pessoa cuidada. O artigo se propõe a ampliar a compreensão de processos sociais como o envelhecimento por meio do cinema, estimulando o uso de filmes em cenários de educação permanente envolvendo pesquisadores, estudantes e trabalhadores de saúde.

Palavras-chave Envelhecimento, Cinema, Dependência, Pesquisa qualitativa 


\section{Introdução}

Este ensaio sobre a utilização de filmes relacionados ao envelhecimento humano com dependência dialoga com dados da pesquisa sobre o tema e visa a contribuir para a formação de profissionais do campo. As autoras partem da hipótese de que a linguagem cinematográfica, traduzida por personagens que desempenham papeis simbolicamente relevantes para expressar problemas de saúde ou sofrimento humano, agrega perspectivas complementares à visão científica ${ }^{2}$ e aguça a sensibilidade dos profissionais para o entendimento das narrativas de seus pacientes. Como ressalta Gadamer ${ }^{3}$ ajuda-os a se colocarem no lugar do outro de modo empático.

Um autor seminal aqui utilizado para compreender as relações entre arte e ciência é Walter Benjamin $^{2}$, que, por meio de sua visão crítica, confrontou o que chamou "ciência das sínteses", que soma cada detalhe do que é observado para se obter a verdade num todo final. O autor mostrou o poder e a presença cada vez mais influente da imagem na definição perceptiva e comunicativa humana frente ao que denominou autoritarismo político e cultural que parametriza ideias e ações cotidianas. Segundo Benjamin, as tecnologias de informação e comunicação permitem uma experimentação da ordem individual e coletiva, temporal e espacial, cujo foco é a intensidade e a sensibilidade humana.

A articulação da arte com a ciência não é um fenômeno novo. É possível identificar exemplos históricos dessa interação em Aristóteles e, mais próximo, em Leonardo da Vinci, que utilizou conhecimentos da matemática e da geometria para revolucionar a representação humana e da natureza. A grande originalidade de Benjamin foi perceber e criar ferramentas conceituais que possibilitassem o contato entre o pensamento lógico e racionalista do discurso filosófico-científico com a linguagem artística, tanto a pautada na literatura quanto a materializada em imagens fotográficas e fílmicas. Sua tese é que, em cada objeto estudado pela ciência há um sentido humano a se manifestar e a cobrar interpretações possíveis. É importante lembrar que o autor viveu os tempos sombrios do nazismo e do stalinismo, uma era sobrecarregada pelos elementos técnicos e administrativos do mundo urbano-industrial, cujos referenciais eram essas grandes narrativas teóricas.

Diante do esfacelamento da vida moderna, do pesadelo da máquina da economia capitalista no período das grandes guerras, Benjamin iden- tificou a arte como um fator potente de elaboração de sentido e de possibilidades para expressão. E ressaltou que da arte emergem os significados mais plausíveis da condição humana. Por isso, propõe um diálogo entre as duas linguagens (a da tecno-ciência e a da arte) e suas lógicas, superando limites interpretativos e metodológicos. E realça, a favor da arte, que a narrativa da experiência individual pode expressar o contexto escalar do coletivo experimentado pela maioria social. E assim, o autor evidencia uma interação dialética entre o individual e o universal e entre os sentidos e os significados das ações humanas.

Deduz-se da obra de Benjamin ${ }^{2}$, a universalidade do conceito de "ideia" que se expressa simbolicamente em palavras e, ao mesmo tempo, contém a imagem do mundo. Cabe ao conhecimento humano relacioná-la com os objetos particulares. Assim, palavra e imagem não podem ser definidas a partir de uma generalização conceitual: elas interagem a partir dos aspectos artísticos presentes em todas as experiências humanas que viabilizam as narrativas propiciadoras de sentido e entendimento.

O cinema, o tema presente neste artigo, permite que se olhe para os detalhes do que os seres humanos realizam no cotidiano por meio de técnicas e de uma linguagem específica em forma de imagens e narrativas. Esse focar em particularidades, típico da linguagem cinematográfica, estabelece condições para que a sensibilidade humana apreenda a lógica da sociedade de seu tempo, por meio da ação de heróis e vilões. Assim, um fragmento consciente (o filme) se transforma num ponto de vista inconsciente, gerando um processo semelhante ao da psicanálise. Nesse processo, há um diálogo entre conhecimento e verdade, sensibilidade e entendimento que inclui paixões e utopias indispensáveis à vida, sem as quais não há humanidade possível.

É dentro dos pontos de vista citados que esta escrita objetiva estimular os possíveis leitores a acrescentarem aos temas de pesquisa, estudo e formação, quaisquer que sejam eles, a perspectiva da arte, em particular, do cinema. Como cita um dos pesquisadores cinéfilos, acerca da importância da arte nos processos de formação de profissionais de saúde, aquele que só sabe medicina, não sabe nada sobre medicina ${ }^{4}$.

A medicina, a despeito dos avanços tecnológicos, segue trabalhando com a palavra, e um de seus instrumentos principais, a anamnese ou a história clínica, está focada no relato do paciente sobre o sofrimento e o mal estar provocado pela doença que o acomete. Em uma exposição 
sobre a importância da literatura [poderíamos acrescentar do cinema] na formação e na prática médica, Baños e Guardiola ${ }^{5}$ afirmam que o sofrimento e as consequências físicas e psicológicas da doença grave sofrida pelo imperador Adriano na Roma imperial, descritas por Marguerite Yourcenar ${ }^{6}$, não são diferentes das apresentadas por pacientes de cardiopatia que vivem hoje em países capitalistas ocidentais. Ou seja, os relatos históricos, literários e fílmicos permitem entender com sensibilidade o adoecimento e o comportamento humano de qualquer época.

Em particular, o cinema pode contribuir, em primeiro lugar, para o entendimento de casos clínicos ao ampliar a compreensão sobre a vida de pessoas pertencentes a outras classes sociais, etnias, gêneros ou territórios. Em segundo lugar, pode auxiliar na formação de médicos e de outros profissionais do campo da saúde por meio do desenvolvimento de competências, hábitos, atitudes, valores e habilidades. Em terceiro lugar, mostra a importância da empatia, da disciplina, da humildade, da perseverança, da honestidade intelectual e pessoal e da capacidade cognitiva e intelectual. Como outros autores, acredita-se que a literatura e o cinema revelam mais sobre a sociedade e sobre o cotidiano do que muitos compêndios técnicos e artigos científicos ${ }^{2,7}$.

Neste ensaio discute-se o uso do cinema na educação em saúde e na formação médica; contextualiza-se o cenário da pesquisa ao qual este texto se articula, traçando um breve perfil da situação do envelhecimento com dependência no Brasil e, ao final, analisam-se os filmes "Poesia" que retrata as dificuldades de uma idosa com doença de Alzheimer e "O que terá acontecido com Baby Jane", uma abordagem da delicada e complexa relação entre a díade cuidador e pessoa dependente.

\section{Trajeto metodológico}

Este ensaio tem por objetivo refletir acerca do tema do envelhecimento com dependência por meio da linguagem fílmica. Para Theodor Adorno ${ }^{8}$ o ensaio é um exercício intelectual crítico e reflexivo em que aparece a subjetividade do autor e, diferente da forma classificatória da ciência, aposta nas mudanças qualitativas que ocorrem nos fenômenos analisados por meio da emoção que a arte desperta no observador ${ }^{9,10}$.

A reflexão sobre o envelhecimento com dependência está inserida na pesquisa denominada "Estudo Situacional dos Idosos Dependentes", cujo objetivo principal foi conhecer a situação desse grupo que vive com suas famílias e das pessoas que os cuidam, com o intuito de subsidiar propostas para uma política sobre a velhice com dependência no Brasil.

Neste ensaio, o objetivo foi trazer para o setting da pesquisa ${ }^{1}$, reflexões cinematográficas acerca da velhice com dependência e da complexa relação entre cuidadores e pessoas cuidadas.

Dentre a extensa produção cinematográfica produzida nos últimos anos abordando temas relativos ao envelhecimento, foram escolhidas duas obras para serem analisadas. A primeira delas é Poesia ${ }^{11}$, um filme oriental, dirigido por Lee-Chang-Dong, em 2010, que mostra a situação de idosos que sofrem com a perda de autonomia física, mental/emocional, cognitiva e social.

$\mathrm{O}$ segundo deles, $\mathrm{O}$ que terá acontecido com Baby Jane ${ }^{12}$, um filme americano dos anos 1960, explora as estratégias de cuidado, no caso do não cuidado utilizadas por familiares para lidar com a idosa com dependência. Embora, sexagenário o filme permanece atual em relação à problemática apresentada.

Nos dois filmes discutidos, são retratados alguns dos inúmeros problemas enfrentados pelos idosos dependentes. Em Poesia, a questão principal é a doença de Alzheimer e em O que terá acontecido com Baby Jane? é a dependência física provocada por um acidente automobilístico, acompanhada pela vivência de violências perpetradas durante uma vida inteira de ressentimentos entre a idosa e a irmã cuidadora.

No trajeto da pesquisa ${ }^{1}$ não foram realizadas entrevistas com idosos portadores de doença de Alzheimer, pelo fato de que dificilmente eles poderiam interagir com os pesquisadores. Mesmo assim, escolheu-se um filme que aborda esta patologia, devido à elevada prevalência deste agravo no Brasil, além do fato de que houve muitos relatos de perda de memória verbalizados pelos idosos e cuidadores que fizeram parte da pesquisa.

Os filmes foram analisados a partir dos temas referentes às vulnerabilidades de gênero, de classe social e do envelhecimento com dependência e, embora não faça parte da metodologia de um ensaio, as situações apresentadas nos filmes podem ser extrapoladas para outros locais.

Ambos os filmes esmiúçam as implicações subjetivas, sociais e econômicas e o manejo das diferentes situações vivenciadas pelos idosos e por seus cuidadores, que na maioria dos países, assim como nos filmes apresentados, são mulheres.

Articular uma visão cinematográfica à investigação significa agregar, aos dados empíricos, 
um olhar e um ponto de vista compreensivo ao tema que muitas vezes permanece opaco na entrevista clínica ou de pesquisa.

\section{Idosos dependentes no Brasil}

No Brasil, a doença de Alzheimer (DA) é responsável por $50 \%$ a $60 \%$ dos casos de dependência das pessoas idosas e é a causa mais frequente de demência senil no mundo. A DA é uma síndrome caracterizada por um declínio crônicodegenerativo progressivo nas áreas da cognição, função e comportamento, com comprometimento das atividades de vida diária. A doença apresenta um curso lento e progressivo e vários padrões deficitários, sendo o mais comum o que tem um início insidioso, com déficits precoces na memória recente ${ }^{13}$. O diagnóstico na fase inicial do Alzheimer é importante para retardar o desenvolvimento da doença e melhorar o bem estar e a qualidade de vida. O declínio da memória e da capacidade de pensar são reflexos da morte celular progressiva que ocorre com a evolução da doença, diferente da perda relativamente menor das células cerebrais que acontecem no processo natural do envelhecimento ${ }^{14}$.

No Brasil há, atualmente, mais de 30 milhões de idosos, fato resultante do crescimento demográfico de 50\% nos últimos 10 anos. Em 2007 eram 17 milhões de pessoas acima de 60 anos e, em 2027, estima-se que esta população chegará a 37 milhões, passando de $8 \%$ no ano 2000 para $19 \%$ em 2030. Atualmente, a maioria da população idosa brasileira está ativa, atuante e contribui social, política e financeiramente para a sociedade onde vive ${ }^{15}$.

As famílias constituem o principal suporte para uma pessoa idosa sadia ou dependente, proporcionando-lhe cuidado e apoio econômico e social. Mas o mesmo lar que protege, pode ser o ambiente violento que lhe tolhe a autonomia, que a discrimina, que por dificuldades financeiras ou por conflitos internos, leva-a a desejar ou a tentar a morte, conforme se constata em pesquisa sobre suicídio nessa faixa etária ${ }^{16-19}$.

$\mathrm{Na}$ população idosa, o grupo mais vulnerável é formado por pobres, mulheres, pessoas que vivem sozinhas, que moram nas ruas ou em isolamento social. Desse conjunto, os que mais sofrem, são as pessoas em situação de dependência, ou seja, as que perdem capacidade funcional, autonomia ou são socialmente desvalidas e, por isso, exigem cuidados familiares permanentes e aumentam a demanda de atenção médica e serviços sociais ${ }^{20,21}$. O último estudo que traça o quadro dos idosos dependentes brasileiros foi realizado pela Pesquisa Nacional de Saúde (PNS), realizada em conjunto pelo Instituto Brasileiro de Geografia e Estatística (IBGE) e Ministério da Saúde (MS) em 2013. Esses dados, analisados por autores como Lima-Costa et al. ${ }^{22}$, mostram que foram ouvidas 23.815 pessoas, numa amostra nacionalmente representativa de toda a população acima de 60 anos. Encontrou-se a prevalência de 30,1\% de pelo menos uma limitação para o exercício das atividades da vida diária (AVD) - um conceito utilizado universalmente para definir a dependência - chegando a $43 \%$ entre os analfabetos; a $29 \%$ entre os que tinham instrução primária e 13,8 \% entre as pessoas com formação superior. Essas informações mostram a elevada proporção dos dependentes, assim como os efeitos da persistente desigualdade social.

\section{Sobre o filme "Poesia": a face feminina e vulnerável da velhice}

Considerando a elevada prevalência da doença de Alzheimer na população brasileira, escolheu-se o filme Poesia para representar o cenário de vida de uma idosa em estágio inicial da doença. Poesia é um filme oriental, datado de 2014, que segundo o crítico de cinema Inácio Araújo ${ }^{23}$ mostra o encontro da "sutileza com a violência".

Embora seja oriental, o filme transcende o local de origem e poderia referir-se a qualquer região urbana de países capitalistas periféricos. A personagem principal é a senhora Yang, uma mulher de 65 anos que vive modestamente numa cidade do interior da Coreia do Sul. A personagem encontra-se em situação de pobreza, recebendo uma aposentadoria de valor irrisório, que lhe exige complementar a renda, trabalhando como cuidadora e doméstica na casa de outro idoso. Essa é a situação de muitas mulheres idosas em vários países e observada na pesquisa de campo aqui mencionada ${ }^{1}$.

No Brasil, o envelhecimento populacional vem acontecendo de forma acelerada num cenário de extremas desigualdades sociais, raciais, de gênero e desemprego estrutural, não havendo garantia de equidade entre os grupos etários na partilha de recursos e na atenção à saúde. Prevê-se que a mudança no regime previdenciário ora instaurada, implicará, como aconteceu em outros países, no aumento da pobreza entre os idosos, grupo historicamente desfavorecido ${ }^{24}$. É nesse contexto que se observa a feminização da velhice e a acumulação das funções de cuidado para com outros membros da família. As mulhe- 
res são mais expostas à violência patrimonial e econômica, e uma forma desse tipo de violência é a provisão de cuidados informais sem remuneração ${ }^{25,26}$.

Em Poesia, a primeira cena - um corpo que desce na correnteza de um rio - vai se repetir na última, ao modo cíclico tão a gosto de filmes orientais. Meninos que brincam nas margens identificam o corpo de uma jovem que se suicidou. Mais tarde sabe-se que ela foi vítima de abuso sexual perpetrado na escola por seis colegas, um deles neto da protagonista. Os estupradores são meninos de famílias abastadas, exceto o último que vive com a avó, a senhora Yang, já que a mãe trabalha em outra cidade.

A senhora Yang vai ao hospital para uma consulta ambulatorial apresentando queixa de dor osteomuscular e se depara, impactada, com o desespero da mãe frente ao corpo da menina que se jogou da ponte. Na consulta, o médico relativiza o problema ósseo e mostra-se atento para o esquecimento seletivo que ela apresenta, o que prenuncia a doença de Alzheimer, embora ela não pareça se importar com esse diagnóstico.

A senhora Yang cuida do neto adolescente, serve-lhe as refeições, cuida de sua roupa. Permanece em pé, silenciosa, pronta para servi-lo, enquanto ele mastiga a janta, reclama da comida, assiste à televisão ou consulta o celular. Ela conversa todos os dias com a filha por telefone, porém só lhe conta boas notícias, como se seguisse o script de uma sociedade onde todos são obrigados a estar felizes. Conta à filha, em tom de brincadeira, que se inscreveu num curso de poesia e que precisa escrever um texto poético. Por causa dessa iniciativa, passa a realizar observações sobre o cotidiano e as anota num caderninho, em busca de inspiração e sentido.

Chamada para uma reunião dos pais dos meninos que haviam praticado o abuso sexual contra a menina que se suicidou, Yang observa que esses homens não demonstram compaixão para com a adolescente violentada e sua família. Aparecem claramente na reunião dos pais de classe média ascendente a indiferença com o estupro e o suicídio da menina, o descaso com a velha senhora e multiplicam-se as desculpas em relação ao comportamento abusivo dos filhos. Esses homens, reunidos para beber e livrar seus filhos de qualquer punição, deixam evidente a interseccionalidade entre gênero, classe social e geração. A única preocupação deles é salvar a imagem dos filhos e abafar o caso.

Como solução para a situação, os pais propõem dividir entre si uma quantia para indenizar a mãe que perdeu a filha e pedir-lhe que esqueça o ocorrido. $\mathrm{O}$ valor proposto para a indenização era muito elevado para Yang. Porém, além de não livrá-la da quantia estipulada, deram-lhe a incumbência de ir à família da jovem suicida portando a proposta do grupo, pois, como diziam, por ser mulher, ela saberia conversar melhor.

Ao contrário dos homens, a senhora Yang mostra-se cada vez mais sensibilizada com o ocorrido. Ela vai ao encontro da mãe da menina que trabalha na região rural. Mas, no caminho já não lembra mais do que foi fazer. Conversa amenidades com a jovem mulher, quando de repente sua memória volta. Com semblante tenso, afasta-se da propriedade, sem ter mencionado a proposta que fora levar. No trajeto de volta, ao encontrar pequenas frutas amarelas caídas das árvores, escreve no caderninho de notas, como uma premonição: os abricós se lançam no chão. Pisoteados e amassados passam para a outra vida.

Enquanto os fatos ocorrem, a senhora Yang persiste no curso de poesia, debatendo-se com as palavras e atenta aos pequenos fatos do cotidiano. Ela permanece aflita por não ter dinheiro para pagar a sua parte no acordo entre os pais. Para obtê-lo, aceita se relacionar sexualmente com o idoso de quem cuida e que a assedia. $\mathrm{O}$ filme traz à tona a permanência, na velhice, da vulnerabilidade feminina à violência sexual e ao machismo masculino.

Do curso de poesia participa também um inspetor da polícia, responsável pela investigação do estupro e morte da estudante. Sabendo que a senhora Yang é avó de um dos meninos implicados, ele lhe dirige perguntas capciosas e ela se confunde ao responder, acreditando mais tarde que poderia ter, inadvertidamente, incriminado seu neto. Em uma das cenas finais do filme, ela joga pingue-pongue com o neto no pátio do bloco residencial onde vive, quando a viatura policial se aproxima e o menino é levado pelos policiais. Embora tenha cumprido sua parte na compensação econômica à família da jovem suicida, seu neto, o menino mais pobre do grupo é preso e responsabilizado. O autor do drama sugere o viés de classe social que impregna o sistema jurídico e policial, uma vez que ele foi o único dos jovens levado para a prisão.

Na ultima aula do curso, a avó deixa uma poesia em memória a Agnes, a menina violada. Sensibilidade e sofrimento, "sutileza e violência". Sobrecarregada física e emocionalmente pela pobreza, pela necessidade de seguir trabalhando como empregada para sobreviver, pelo suicídio da jovem, pelo cuidado do neto e pela tentativa 
frustrada de livrá-lo da punição, pela iniquidade do tratamento oferecido pelo sistema de justiça, pela memória se esvaindo, a velha senhora escreve uma poesia e se lança ao rio, como "os abricós que se lançam no chão. Pisoteados e amassados passam para a outra vida".

Um filme é sempre polissêmico. Mas ao personalizar as questões em protagonistas fortes como é feito em Poesia, este permite muitas observações: (1) a sobrecarga da avó responsável por um neto adolescente que ignora o trabalho despendido para mantê-lo; (2) uma senhora que esconde da filha informações sobre seus problemas e sofrimento, para não aborrecê-la; (3) um idoso dependente rico, autoritário e abusivo que paga mal a quem o cuida a ponto da cuidadora sentir-se obrigada a vender-lhe serviços sexuais, uma violência chancelada pela sociedade patriarcal; (4) por ser mulher, pobre e idosa, Yang é desrespeitada pelos pais dos garotos, pelo inspetor de polícia, pela filha que terceirizou os cuidados com o neto, pelo idoso que a assedia; (5) sem tempo e consciência para cuidar do Alzheimer, a velha senhora comete suicídio, lançando-se no rio. Este é o desfecho de uma vida desprotegida e desamparada.

O suicídio de idosos e também de crianças, tratado com delicadeza pelo filme, é um dos problemas vivenciados em muitos países, inclusive no Brasil, particularmente associado ao isolamento social e afetivo e às violências que se encadeiam podendo parecer insolúveis e, em geral, associadas a problemas psicológicos, relacionais, sexuais, econômicos ou geracionais ${ }^{16}$.

\section{Sobre o filme "O que terá acontecido com Baby Jane?" amor e ódio entre cuidadora e pessoa dependente}

No cuidado familiar ao idoso dependente há uma nítida divisão sexual de papeis: mães, esposas, filhas ou parentes são a maioria. Na pesquisa aqui citada ${ }^{1}$ elas constituem $88,7 \%$ dos cuidadores familiares e $93,3 \%$ dos cuidadores formais. Essas mulheres realizam, de modo gratuito ou com salários irrisórios, grande parte do trabalho de cuidado, quer seja o de crianças, de pessoas com necessidades especiais ou de idosos ${ }^{27}$. No Brasil, embora as políticas públicas de amparo aos velhos considerem a família, o Estado e a sociedade igualmente responsáveis pelo cuidado, na prática, ele tem sido realizado como questão da vida privada, de modo que seu desempenho fica a cargo da família, materializado na figura da mulher ${ }^{28}$.
Assim, o cuidado prestado aos idosos, principalmente em situação de dependência, representa uma sobrecarga financeira, social e emocional a quem cuida. Sentimentos de desespero, cansaço, ansiedade, angústia, desamparo são frequentes em famílias de cuidadores de doentes crônicos e graves, além do ressentimento e da exclusão social que sofrem por não encontrarem tempo e espaço para realizar atividades profissionais, de autocuidado e de lazer ${ }^{29-31}$.

A dependência física exige muito empenho por parte de quem cuida, pois essa pessoa passa a complementar o que a outra pode ou não fazer. Por estar intrinsecamente vinculado ao relacionamento com o outro, o idoso que perde a autonomia para realizar as atividades da vida diária costuma sofrer maus tratos de todas as ordens quando quem o assiste foi maltratado por ele durante a vida ou quando há ressentimento e falta de empatia entre ambos ${ }^{21}$.

Muitos filmes mostram uma situação que hoje é corrente no Brasil, a de idosos cuidando de outras pessoas idosas da família, sobrecarregados financeira e emocionalmente. O filme O que terá acontecido com Baby Jane, um drama psicológico dos anos 1960, mostra a relação conturbada entre duas irmãs já idosas. Jane, a cuidadora havia sido uma estrela de cinema mirim e Blanche, a que é cuidada, fora uma atriz de filmes adultos, e atualmente sofre as sequelas de um acidente automobilístico. Ambas são marcadas pelos maus tratos sofridos na infância. Jane não ia à escola $\mathrm{e}$ nem convivia com outras crianças, pois seu tempo era dedicado a ensaios e apresentações, sendo pressionada pelos pais para alcançar fama e riqueza. Blanche era ignorada, considerada sem graça e sem talento ${ }^{32}$. Ao longo do tempo, o roteiro se inverte, Jane é esquecida por seu desempenho ser considerado medíocre e Blanche torna-se uma atriz reconhecida e bem sucedida economicamente.

A velhice dessas duas mulheres se passa numa casa ampla e confortável, em que dinheiro não é problema. Porém, a relação de cuidado e parceria que poderia se estabelecer entre elas se configura como uma relação de violência, cuja intensidade aumenta ao longo da trama. Jane é dependente do álcool e, pelas circunstâncias, se torna uma cuidadora de Blanche, função que desempenha de modo rude, autoritário e sem empatia.

A comunicação entre as irmãs é permeada por segredos que se desvendam aos poucos. Blanche quer vender a casa que é de sua propriedade e colocar a irmã numa clinica para tratamento do alcoolismo. Mas Jane controla o espaço: escuta os 
telefonemas de Blanche, passa a impedi-la de se comunicar com o exterior, simula sua voz para autorizar compra de bebidas, desmarca suas consultas médicas e adultera seus cheques. Coroa sua maldade, dispensando a empregada que as servia e mostrava simpatia pela idosa dependente.

No filme, os maus tratos vão se intensificando e se tornando mais graves. Jane mata o passarinho de estimação de Blanche, oferece-lhe comida deteriorada ou a deixa sem comer, além de sedá -la, subjugá-la, machucá-la e colocá-la em prisão domiciliar. O drama mostra um caso extremo, mas evidencia situações de mal estar, negligência, abusos e violência, muitas vezes escondidos pelos cuidadores. Duas irmãs, solitárias, adoecidas e frágeis, vivenciando sentimentos de competição e raiva que alimentaram ao longo da vida e se transformaram num presente em que ambas continuam presas numa relação de des(cuidado). Jane anestesia-se no álcool, nas lembranças do passado, procurando reviver a juventude e a fama perdidas. Blanche, por sua vez, não consegue conversar francamente com a irmã e a mantém presa na culpa e na ignorância de um segredo que quem assiste só fica sabendo ao final.

A violência que ocorre entre Jane e Blanche não é uma situação inédita. No Brasil, o Disque 100-Idoso recebeu, em 2019, mais de 37 mil denúncias sobre violência contra idosos, o que deve ser considerado como uma pequena amostra daquilo que realmente acontece (a maioria deles não tem coragem nem força para dar queixa sobre os maus tratos que sofrem, particularmente, por parte dos familiares). Do total notificado, $38 \%$ o foram por negligência, $26 \%$ por violência psicológica (xingamentos, humilhação, por exemplo); $20 \%$ por abusos financeiros e patrimoniais e $12 \%$ por violência física ${ }^{33}$. Observa-se que todas essas modalidades estão presentes na situação de Blanche. Ainda que a maioria dos maus tratos não deixe marcas no corpo, Jane priva a idosa de cuidados, de afeto e de alimentos, ataca sua moral e sua autoestima, além de usufruir dos bens e do patrimônio da irmã, como observado em diversas pesquisas ${ }^{21,34}$.

$\mathrm{Na}$ pesquisa que motiva este artigo e trata dos idosos dependentes e seus cuidadores ${ }^{1}$, muitos familiares fizeram declarações de afeto, cuidado e empatia, embora tenha havido relatos de brigas, negligências e descaso. Em algumas entrevistas as críticas foram verbalizadas pelos cuidadores profissionais e omitidas pelos familiares, desejosos de se mostrarem diligentes no cuidado e de evitar qualquer denúncia ou "protegerem a face", como assinalado em Ostermann ${ }^{35}$. Os estudos sobre os agressores de idosos colocam os filhos maltratados, o ambiente violento ou de pouco afeto durante a vida, como algumas das causas associadas aos maus tratos que eles sofrem no final da vida ${ }^{21,36-38}$.

O filme fala particularmente de mulheres. De mulheres que em algum momento de suas vidas tiveram fama e poder e enfrentam o abandono no final da existência. Fala também do isolamento social, considerado um dos fatores mais importantes da violência contra a pessoa idosa. E também ressalta a forma como os meios de comunicação, inclusive o cinema, contribuem para manter estereótipos. Quando se referem às mulheres idosas, eles ainda o fazem, considerando adequadas as que se conformam com a velhice e se comportam de acordo com as normas de gênero destinadas a elas. Em geral, são ridicularizadas as que desejam aparentar juventude. Os rostos e os corpos de Blanche e de Baby Jane revelam aquilo que o patriarcado cobra das mulheres: elas não podem envelhecer, pois o corpo feminino envelhecido é visto com desprezo e decrepitude pela sociedade patriarcal, machista e sexista ${ }^{32}$.

É importante assinalar que o envelhecimento tem um recorte de gênero e incide de modo mais cruel sobre mulheres, empobrecidas ou sobrecarregadas com tarefas de cuidado consigo ou com outros familiares, em dois sentidos. $\mathrm{O}$ primeiro, quanto a sua aparência, o segundo quando as consideram "cuidadoras naturais". O mesmo patriarcado que avalia as mulheres pela aparência destina-lhes os trabalhos domésticos pouco valorizados e incentiva a disputa, a competição, a falta de empatia entre elas. E muitas cumprem esse "destino naturalizado" de forma isolada e solitária, na ausência de políticas públicas e apoio social que as amparem e protejam ${ }^{39}$.

Embora o filme exacerbe os tons dramáticos da relação entre as irmãs, a competição entre elas, os segredos, os maus-tratos, as mentiras e as violências, ele traz uma reflexão sobre o papel de quem cuida e de quem recebe os cuidados e permite analisar, criticamente, perspectivas de gênero, de geração e de classe, capazes de sensibilizar cuidadores e profissionais de saúde.

\section{Algumas considerações}

Poder-se-ia perguntar de que maneira os filmes contribuem para o entendimento de temas de pesquisa, incluindo os do envelhecimento. Um filme é sempre polissêmico e prende o expectador pela sensibilidade que consegue despertar, 
como lembra Benjamin ${ }^{2}$. A hipótese é de que ao personalizar questões humanas de imenso significado, eles tocam o fundo da alma e do coração. E do ponto de vista humano, nada que não passe pelos afetos consegue se tornar uma prática transformadora.

Um aspecto a considerar quando se utiliza o cinema de modo complementar a atividades de pesquisa, observações clínicas ou atividades pedagógicas é a decodificação da linguagem visual que inclui observação, análise e leitura das imagens, utilização dos planos, compreensão da trama e do entrelaçamento das histórias, assim como a sequência não linear da narrativa, incluindo tempos diversos e reconstituição de memórias. Para Samain ${ }^{40}$ há muito que desvendar no dentro e no atrás das imagens, sem esquecer a ampliação da experiência estética produzida por elas. No entanto, o seu uso é complementar e não substitui os temas técnicos e a problematização de situações da vida real ${ }^{41}$.

Este texto busca reforçar a potência da arte no estudo do envelhecimento, tanto em relação à formação de estudantes, à educação permanente de trabalhadores de saúde, quanto à discussão de temas de pesquisa e de casos clínicos. Pelo seu alcance como meio de comunicação, que junta arte, ciência, técnica, experiência e criatividade, o cinema é um meio potente de que as sociedades dispõem para olharem para si mesmas, identificando seus problemas e mazelas sociais. Desta forma, ele contribui para ampliar a autocrítica e o autoconhecimento ${ }^{42}$.

Atualmente, o idoso tem aparecido no cinema cada vez mais como personagem e protagonista, quebrando, de certa maneira, a longa conspiração de silêncio em relação à velhice, como afirma Guita Debert ${ }^{43}$ e configurando uma nova tipo$\operatorname{logia}$ o gerontocine $e^{44}$. Pode-se afirmar que essa forma de arte está contribuindo para a construção de uma percepção social mais fiel e adequada sobre o envelhecimento, embora muitos filmes ainda associem velhice com doença e morte.

Em suma, a linguagem simbólica, imagética e metafórica do cinema aporta recursos para se conhecerem construções socioculturais acerca de saúde-doença e de situações singulares de agravos e dores; para compartilhar experiências de cuidado, de promoção da saúde e da vida; e para ampliar as possibilidades de entendimento do sofrimento e das limitações humanas, como é o caso da velhice com dependência.

\section{Colaboradores}

SN Meneghel e MCS Minayo participaram de todas as etapas da elaboração do artigo: concepção, marco referencial, análise, discussão, palavras finais. 


\section{Referências}

1. Minayo MCS, Figueiredo AEB, Mangas RMN, Silva RM, Vieira LJES, Souza GS, Meneghel SN, Gutierrez DMD, Figueiredo MLF, Mendonça JMB. Estudo Situacional dos Idosos Dependentes. Rio de Janeiro: ClavesFiocruz; 2019.

2. Benjamin W. Magia e técnica, arte e política. São Paulo: Brasiliense; 1985.

3. Gadamer G. Verdade e método. Petrópolis: Editora Vozes; 1999.

4. D'Ottavio AE, Sanchez JEG, Sanchez EG. The cinema as a fostering tool for health area undergraduates. Rev. Med Cine 2019; 15(2):101-105.

5. Baños J, Guardiola E. Medicina y literatura: el valor de las palabras. Rev Med Cine 2015; 11(1):3-4.

6. Yourcenar M. Memórias de Adriano. Rio de Janeiro: Nova Fronteira; 2015.

7. Marinas JM, Santamaria C, organizadores. La historia oral: métodos y experiencias. Madrid: Mistral; 1993.

8. Adorno TW. O ensaio como forma. In: Adorno TW. Notas de literatura I. São Paulo: Editora 34; 2003. p. 15-45.

9. Meneghetti FK. O que é um ensaio-teórico? Rev. Adm. Contemp. 2011; 15(2):320- 332.

10. Gatti LF. Como escrever? Ensaio e experiência a partir de Adorno. Cadernos de Filosofia da Puc-Rio 2014; 23(35):161-187.

11. Lee-Chang-Dong. Poesia [filme]. Seul; 2010.

12. Aldrich R. What ever happened to Baby Jane? [filme] Hollywood; 1962.

13. Gonçalves EG, Carmo JS. Diagnóstico da doença de Alzheimer na população brasileira: um levantamento bibliográfico. Rev. Psicol Saúde 2012; 4(2):170-176.

14. Diamond J. Report on Alzheimer's disease and current research. Toronto: Alzheimer Society of Canada; 2008.

15. Camaramo AA. Cuidados de longa duração para a população idosa: um novo risco social a ser assumido? Rio de Janeiro; IPEA; 2010.

16. Cavalcante FG, Minayo MCS, Meneghel SNM, Silva RM, Gutierrez DM, Conte M, Figueiredo AEB, Grubits S, Cavalcante AC, Mangas RMN, Vieira LJES, Moreira GAR. Autópsia psicológica e psicossocial sobre suicídio de idosos: abordagem metodológica. Cien Saude Colet 2012; 17(8):2039-2052.

17. Figueiredo AEB, Silva RM, Mangas RMN, Vieira LJES, Furtado HMJ, Gutierrez DMD, Sousa GS. Impacto do suicídio da pessoa idosa em suas famílias. Cien Saude Colet 2012; 17(8):1993-2002.

18. Minayo MCS, Cavalcante FG. Tentativas de suicídio entre pessoas idosas: revisão de literatura (2002/2013). Cien Saude Colet 2015; 20(6):1751-1762.

19. Meneghel SN. Algumas reflexões acerca do suicídio e do comportamento suicida. In: Minayo MCS, organizador. Comportamento suicida de idosos. Fortaleza: Edições UFC; 2016. p. 93-118.

20. Lima-Costa MF, Matos DL, Camargo VP, Macinko J. Tendências em dez anos das condições de saúde de idosos brasileiros: evidências da Pesquisa Nacional por Amostra de Domicílios (1998, 2003, 2008). Cien Saude Colet 2011; 16(9):3689-3696.

21. Minayo MSC. Violência contra a Pessoa Idosa: é possível prevenir e é necessário superar. Brasília: SEDH; 2014.
22. Lima-Costa MF, Manbrini JVM, Peixoto SV, Malta DC, Macinko J. Socioeconomic inequalities in activities of daily living limitations and in the provision of informal and formal care for non institutionalized older Brazilians: National Health Survey, 2013. Int J Equity Health 2016; 15(1):137-145.

23. Araújo I. Filme coreano Poesia é o encontro da sutileza com a violência. Folha de São Paulo. 14.11.2014.

24. Viana ALA, Silva AP. Meritocracia neoliberal e capitalismo financeiro: implicações para a proteção social e a saúde. Cien Saude Colet 2018; 23(7):2007-2017.

25. Cunha ARS, Silva MRF. Direitos e políticas públicas para o idoso no contexto do estado neoliberal brasileiro. II Congresso Nacional de Envelhecimento Humano. SESI: Curitiba; 2018.

26. Oxfam. Relatório sobre nós e a desigualdade "tempo de cuidar". Fórum Econômico Mundial de 2020, Davos. [acessado 2020 Jan 31]. Disponível em: https://oxfam. org.br/justicasocial-e-economica/forum-economicode-davos/tempo-de-cuidar/

27. Karsch UM. Idosos dependentes: famílias e cuidadores. Cad Saude Publica 2003; 19(3):861-866.

28. Kuchemann BA. Envelhecimento populacional, cuidado e cidadania: velhos dilemas e novos desafios. Soc. Estado 2012; 27(1):165-180.

29. Matsuda CMCB. Sobrecarga e saúde mental em cuidadores de idosos com demência ou com depressão [dissertação]. São Paulo: Faculdade de Medicina da Universidade de São Paulo; 2004.

30. Camargo RCVF. Implicações na saúde mental de cuidadores de idosos: uma necessidade urgente de apoio formal. Rev. Eletrônica Saúde Mental Álcool Drog. 2010; 6(2):231-254.

31. Freitas IBA, Meneghel SN, Selli L. A construção do cuidado pela equipe de saúde e o cuidador em um programa de atenção domiciliar ao acamado em Porto Alegre (RS, Brasil). Cien Saude Colet 2011; 16(1):301-310.

32. Simões I. O que terá acontecido a Baby Jane? e o envelhecimento feminino como fator violento. [acessado 2020 Jan 31]. Disponível em: https://deliriumnerd. com/2019/07/30/o-que-tera-acontecido-a-baby-janehenry-farrell-resenha/

33. Brasil. Disque 100 - idosos 2019. Brasília: MDH; 2020.

34. Meneghel SN, Moura R, Heller LZ, Gutierrez DMD. Tentativa de suicídio em mulheres idosas, uma perspectiva de gênero. Cien Saude Colet 2015, 20(6):17211730.

35. Ostermann AC. Comunidades de prática: gênero, trabalho e face. In: Heberle VM, Ostermann AC, Figueiredo DC, organizador, Linguagem e gênero no trabalho, na mídia e em outros contextos. Florianópolis: Editora da UFSC; 2006. p. 15-47.

36. Anetzberger G. Caregiving: Primary cause of elder abuse? Generations 2000; 24(2):46-51.

37. Leite MT, Hildebrandt LM, Santos AM. Maus-tratos a idosos no domicílio: concepção de familiares. Rev Bras Geriatr Geront 2008; 11(2):209-221.

38. Minayo MCS, Figueiredo, AEB, Mangas RMN. O comportamento suicida de idosos institucionalizados: histórias de vida. Physis 2017; 27(4):981-1002. 
39. Mendonça MLM, Ferreira C. Envelhecimento feminino, consumo e protagonismo. É a (voz da) vovozinha! Comunicação, Mídia e Consumo 2014; 11(32):119136.

40. Samain E. O fotográfico. Rio de Janeiro: Hucitec; 1998.

41. Ibanez LMM, Bertilotti L, Debenedetti S, Degrossi C, Marcos HA. Aplicación del cine como estrategia didáctica para la enseñanza de la investigación científica. Rev Med Cine 2010; 6(1):24-28.

42. Holgado CT, Perdigueiro-Gil E. El cine y las dimensiones colectivas de la enfermedad. Rev Med Cine 2011; 7(2):44-53.

43. Debert GG. A vida adulta e a velhice no cinema. In: Gusmão NMM. Cinema, velhice e cultura. Campinas: Alinea; 2004. p. 25-43.

44. Roca-Carrió E. De Cameron a Haneke: un punto inicial para analizar el cine gerontológico. Rev Med Cine 2015; 11(2):105-108.

Artigo apresentado em 01/07/2020

Aprovado em 18/08/2020

Versão final apresentada em 20/08/2020

Editores chefes: Maria Cecília de Souza Minayo, Romeu Gomes, Antônio Augusto Moura da Silva. Editora Associada da área de Saúde do Idoso: Joselia Oliveira Araújo Firmo 